\title{
OTIMIZAÇÃO DE MEIO DE CULTURA PARA PRODUÇÃO DE BIOMASSA DE Bacillus thuringiensis POR METODOLOGIA DE SUPERFÍCIE DE RESPOSTA
}

\section{G. MARÇAL ${ }^{1}$; T.D.M de MEDEIROS ${ }^{1}$; D.F COELHO ${ }^{2}$; B. ZANCHETTA ${ }^{2}$; P.G. MAZZOLA $^{3}$; V.L CARDOSO ${ }^{4}$; U.COUTINHO-FILHO ${ }^{4}$; L.R. GOULART ${ }^{1}$; E. SILVEIRA ${ }^{1}$}

${ }^{1}$ Universidade Federal de Uberlândia, Instituto de Genética e Bioquímica.

${ }^{2}$ Universidade Estadual de Campinas, Faculdade de Engenharia Química.

${ }^{3}$ Universidade Estadual de Campinas, Faculdade de Ciências Medicas.

${ }^{4}$ Universidade Federal de Uberlândia, Faculdade de Engenharia Química.

E-mail para contato: tiagodaniel.biotecufu@yahoo.com.br

\begin{abstract}
RESUMO- O microrganismo Bacillus thuringiensis é amplamente utilizado no controle biológico de pragas, sendo alvo de pesquisas na área de genética, e otimização de processos fermentativos. A otimização de seu processo é importante visto a importância da aplicação e do mercado relacionado a seu uso. Um dos principais aspectos da produção a ser otimizado é o meio de cultura, devido sua participação significativa no custo final do produto, sendo comum as pesquisas relacionadas a aplicação de resíduos agroindustriais. O estudo visou descobrir as concentrações ideais de resíduos agroindustriais para que houvesse maior produtividade com menor custo, encontrando como o meio de cultura ideal aquele com as seguintes concentrações: Proteína de soja $44 \mathrm{~g} / \mathrm{l}$, Milhocina e Sacarose 30 g/l, Sulfato de Ferro 0,55 g/1, Sulfato de Magnésio 0,01 g/L, Sulfato de Manganês $0,01 \mathrm{~g} / \mathrm{L}$ e Sulfato de Zinco $0,1 \mathrm{~g} / \mathrm{L}$, pH 6,0 , agitação $100 \mathrm{rpm}$ e temperatura $25^{\circ} \mathrm{C}$.
\end{abstract}

\section{INTRODUÇÃO}

O microrganismo Bacillus thuringiensis é uma bactéria do gênero Bacillaceae, isolada da traça da farinha e descrita na Alemanha em 1915. Se diferencia das outras espécies do seu gênero por ser capaz de sintetizar cristais tóxicos que servem para controle biológico de pragas para plantações, além de vetores de doenças que atingem parcelas consideráveis da população (Angelo, et al., 2010).

Devido essa sua aplicação apresenta grande importância de mercado, sendo alvo frequente de estudos, tanto na área de biologia molecular, visto que seus genes são utilizados para produção de plantas transgênicas resistentes as pragas, quanto na área de otimização de parâmetros da produção da biomassa para aplicação direta (Angelo, et al., 2010).

Para aplicar no campo é necessária uma grande quantidade de biomassa, para obter maior quantidade é necessário melhorar a produção e facilitar a comercialização, podendo ser feito por: mecanismos genéticos, alteração de genes, alteração das vias metabólicas que 


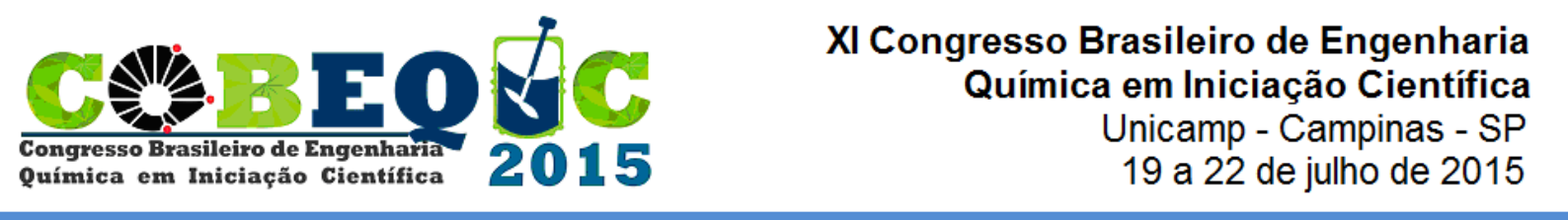

proporcionam maior taxa de divisão celular, e otimização do processo fermentativo (Grizotto, 2005).

Por envolver um design com grande número de parâmetros, a otimização neste caso não favorece a metodologia convencional, pois demandaria um grande número de experimentos, e o tempo de realização inviabilizaria o processo, além deste não permitir identificar corretamente a interação entre fatores, portanto é melhor que haja uso de ferramentas estatísticas para facilitar este processo (Liu e Tzeng, 1998).

Uma dessas ferramentas estatísticas é a metodologia de superfície de resposta, técnica que permite analisar influência de diversos parâmetros em um processo, utilizando diminuto número de experimentos, sendo uma ferramenta de grande valor para otimização (Liu e Tzeng, 1998). Pode ser utilizada na análise da influência de alguns parâmetros, como: concentrações das fontes de carbono, nitrogênio e outros nutrientes, $\mathrm{pH}$, temperatura, agitação e taxa de oxigênio dissolvido, objetivando-se maximizar a produtividade e diminuir os custos (Tari et al., 2007).

\section{MATERIAIS E MÉTODOS}

\subsection{Microrganismo e Pré-Cultivo}

O microrganismo Bacillus thuringiensis foi preservado na forma liofilizada, a temperatura ambiente. Antes da inoculação do microrganismo nos meios para fermentação, foi feito um pré-cultivo em erlenmeyer, em caldo nutriente $(3 \mathrm{~g} / \mathrm{L}$ extrato de carne e $5 \mathrm{~g} / \mathrm{L}$ peptona) colocando $50 \mathrm{~g} / \mathrm{L}$ do microrganismo liofilizado, e incubado em shaker a $37^{\circ} \mathrm{C}, 150$ rpm, durante 24 horas.

\subsection{Design}

Estudos prévios indicaram proteína de soja e sulfato de ferro como componentes do meio de cultura mais significativos no crescimento do microrganismo, com base nisso estabeleceu-se um Composite Central Design (CCD) para avaliar de forma mais criteriosa os efeitos do sulfato de ferro e proteína de soja, utilizando 5 pontos de variação. Além destes foram analisados milhocina e sacarose em duas diferentes concentrações, $+1(30 \mathrm{~g} / \mathrm{L})$ e -1 (10 $\mathrm{g} / \mathrm{L}$ ). Os valores utilizados na composição dos meios são os apresentados na tabela 1 . As análises estatísticas foram feitas utilizando o software Statistica 8 (Statsoft, USA).

Tabela 1 - Valores codificados das variáveis do meio no CCD

\begin{tabular}{lccccc}
\hline Variáveis & -1.414 & -1 & 0 & +1 & +1.414 \\
\cline { 2 - 6 } Proteína de soja $\left(\mathrm{gL}^{-1}\right)$ & 16 & 20 & 30 & 40 & 44 \\
Sulfato de Ferro $\left(\mathrm{gL}^{-1}\right)$ & 0.086 & 0.100 & 0.550 & 1.000 & 1.186 \\
\hline
\end{tabular}




\subsection{Quantificação da Biomassa}

A quantificação da biomassa foi realizada através da retirada de uma alíquota dos meios preparados, após a fermentação, medindo a O.D a $600 \mathrm{~nm}$, as medidas foram realizadas para o meio centrifugado e não centrifugado, subtraindo o valor da O.D do meio centrifugado do valor obtido para o não centrifugado, assim separando a O.D do meio, e deixando somente a O.D da biomassa.

\section{RESULTADOS E DISCUSSÃO}

Os resultados obtidos por esse design estão descritos na tabela 2, indicando a composição dos meios e a quantidade de biomassa obtida por cada meio de cultura. Com base nesses resultados foi feito o gráfico da metodologia de superfície de resposta, indicando a composição do meio ótimo.

Tabela 2 - Design e Resultados da Metodologia de Superfície de Resposta

\begin{tabular}{|c|c|c|c|c|c|c|}
\hline \multirow{3}{*}{ Experimento } & \multirow{2}{*}{\multicolumn{2}{|c|}{$\begin{array}{c}-1 \\
\text { Níveis }\end{array}$}} & \multicolumn{3}{|c|}{ Sacarose e Milhocina } & \multirow{3}{*}{$\begin{array}{c}+1 \\
\text { Biomassa } \\
\left(\text { g. } \text { L }^{-1}\right)\end{array}$} \\
\hline & & & \multirow{2}{*}{$\begin{array}{c}\text { Biomassa } \\
\left(\text { g. } \mathrm{L}^{-1}\right) \\
\end{array}$} & \multicolumn{2}{|c|}{ Níveis } & \\
\hline & $X_{1}$ & $X_{2}$ & & $X_{1}$ & $X_{2}$ & \\
\hline 1 & -1 & -1 & 1.161 & -1 & -1 & 1.369 \\
\hline 2 & -1 & +1 & 0.766 & -1 & +1 & 0.949 \\
\hline 3 & +1 & -1 & 0.974 & +1 & -1 & 1.762 \\
\hline 4 & +1 & +1 & 1.059 & +1 & +1 & 0.867 \\
\hline 5 & $-1,414$ & $\mathbf{0}$ & 0.467 & $-1,414$ & $\mathbf{0}$ & 1.026 \\
\hline 6 & $+1,414$ & $\mathbf{0}$ & 0.693 & $+1,414$ & $\mathbf{0}$ & 2.428 \\
\hline 7 & $\mathbf{0}$ & $-1,414$ & 1.366 & $\mathbf{0}$ & $-1,414$ & 1.576 \\
\hline 8 & $\mathbf{0}$ & $+1,414$ & 1.297 & $\mathbf{0}$ & $+1,414$ & 0.705 \\
\hline 9 & $\mathbf{0}$ & $\mathbf{0}$ & 1.548 & $\mathbf{0}$ & $\mathbf{0}$ & 1.563 \\
\hline 10 & $\mathbf{0}$ & $\mathbf{0}$ & 1.122 & $\mathbf{0}$ & $\mathbf{0}$ & 1.685 \\
\hline 11 & $\mathbf{0}$ & $\mathbf{0}$ & 1.499 & 0 & $\mathbf{0}$ & 1.623 \\
\hline 12 & 0 & 0 & 1.249 & 0 & 0 & 1.663 \\
\hline
\end{tabular}

A figura 1 indica os pontos em que há maior produtividade de biomassa, em menores (a) e maiores (b) concentrações de milhocina e sacarose, pode-se observar que os maiores valores de biomassa produzidos foram aqueles em maiores concentrações de milhocina e sacarose $(+1)$, e no ponto em que a concentração de proteína de soja é $40 \mathrm{~g} / \mathrm{L}$ e do sulfato de ferro é $0,55 \mathrm{~g} / \mathrm{L}$. Sendo este o ponto ótimo determinado para cultivo do microrganismo. 
Destaca-se o efeito significativo da fonte de nitrogênio no crescimento de biomassa, neste caso a proteína de soja.

$\mathrm{Na}$ literatura, é amplamente relatada a importância da fonte de nitrogênio no crescimento, Devidas et al. (2014) testando meios suplementados com diversas fontes de nitrogênio, observou um grande rendimento de produção de biomassa no meio suplementado com proteína de soja. As fontes de nitrogênio apresentaram efeito significativo no crescimento, pela elevada importância na produção de cristais mais tóxicos, as principais fontes foram proteína de soja e milhocina, com resultados positivos para aumento da produção de biomassa. A proteína de soja é um potencial fontes de nitrogênio, visto que possui grande disponibilidade, sendo o cultivo de soja muito encontrado no Brasil.

El-Bendary (2006) descreveu a importância de se acrescentar aminoácidos a fim de observar o crescimento de $B$. thuringiensis em meio mínimo. A cisteína mostraram um efeito inibitório sobre o crescimento, podendo ser explicada a preferência para a proteína de soja, visto que a proteína de soja tem uma concentração mínima de cisteína, e concentrações comparativamente elevadas de valina, leucina, treonina. A importância do sulfato de ferro está relacionada a necessidade dos íons de ferro na estimulação da produção de toxinas Cry.

A importância da interação entre milhocina e sacarose pode estar associada a importância da manutenção de um balanço C:N apropriado, fator importante para que haja um bom crescimento do microrganismo como mostrado (Bratbak 1985; Nagata 1986). Esta interação pode estar associada ao equilíbrio entre as concentrações de carbono e nitrogênio no meio, essencial para que a variação no $\mathrm{pH}$, decorrente da metabolização desses compostos, não ocorra causando prejuízo no crescimento das bactérias. O estimulo da produção de biomassa por sacarose indica a preferência, do B. thuringiensis, por açúcares simples. Estes resultados confirmam os resultados de Devidas et al. (2014), onde houve uma redução na produção de biomassa de $B$. thuringiensis na presença de amido.

Figura 1 - Resultado da análise CCD (a- 10g/L; b- 30g/L de milhocina e sacarose)
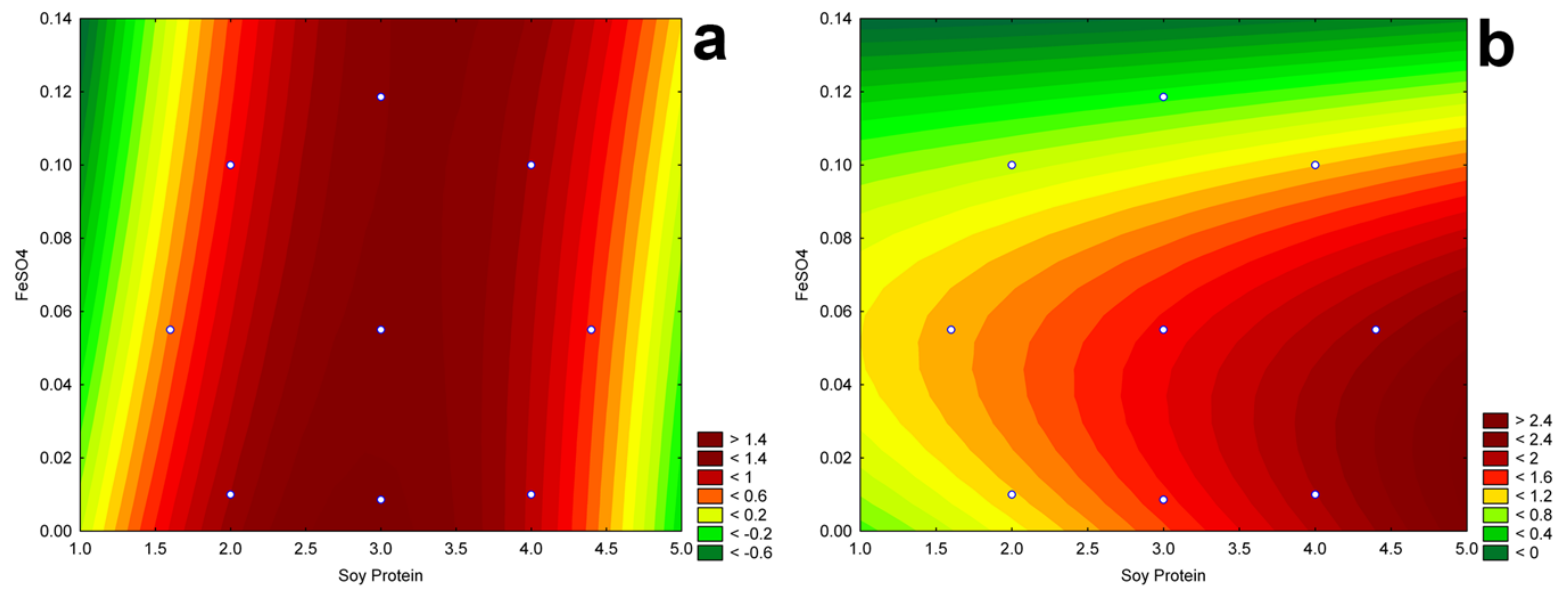

O ganho de biomassa resultante do processo de otimização, é mostrado na figura 2, sendo que houve um aumento de cerca de 12,2 na quantidade de biomassa obtida. 


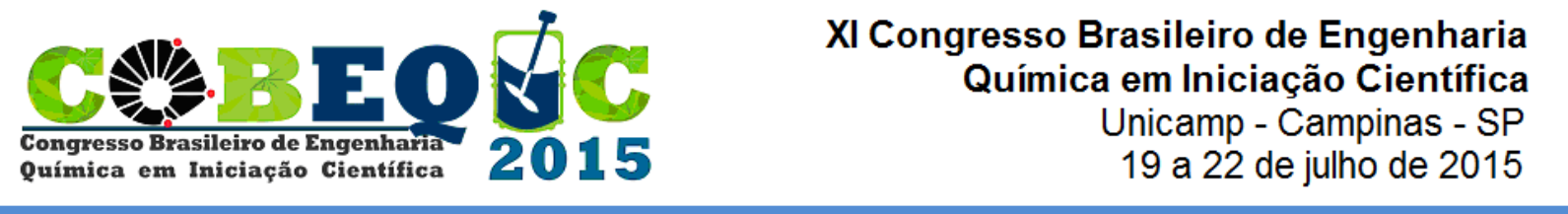

Figura 2 - Produção de Biomassa, antes ( • ) e depois (•) da otimização

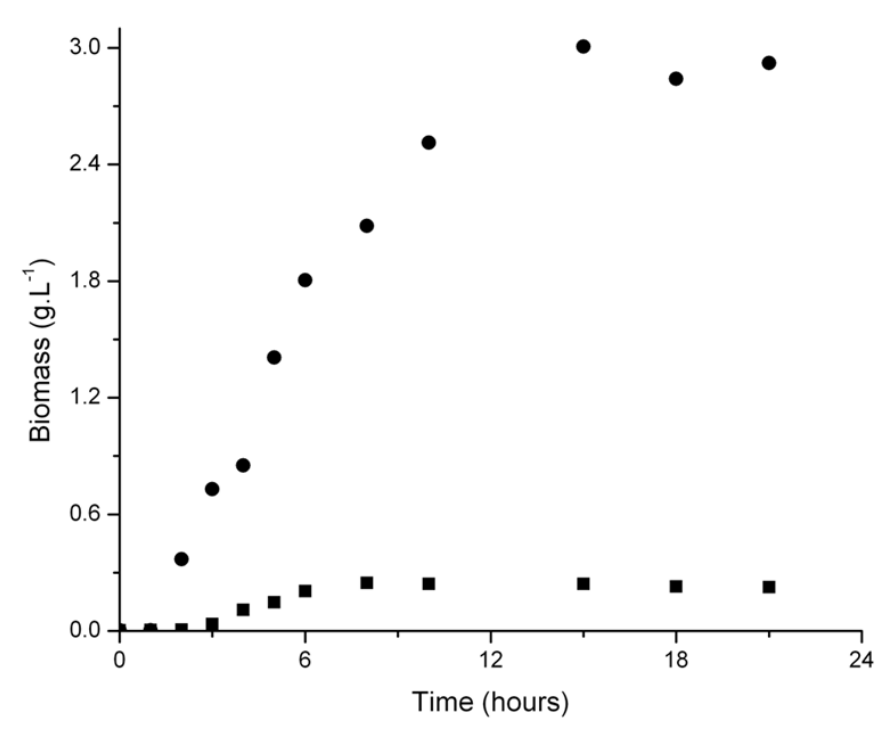

\section{Conclusão}

Os resultados do experimento indicam a importância da fonte de nitrogênio (Proteína de Soja) no crescimento do microrganismo, determinando-se como ponto ótimo aquele em que há $40 \mathrm{~g} / \mathrm{L}$ deste componente. Já para o sulfato de ferro, a concentração ótima é $0,55 \mathrm{~g} / \mathrm{L}$, para milhocina e sacarose a concentração de $30 \mathrm{~g} / \mathrm{L}$ de cada, foram as concentrações que levaram a maior produtividade.

\section{Referências}

ANGElO, E. A., VILAS-BÔAS, G. T., CASTRO-GÓMEZ, R. J. H. Bacillus thuringiensis: general characteristics and fermentation. Semina: Ciências Agrárias, v. 31, n. 4, p. $945-$ $958,2010$.

BRATBAK, G. Bacterial Biovolume and Biomass Estimations. Appl Environ Microbiol, v. 49, p. 1488-1493, 1985.

DEVIDAS P. C.; PANDIT B. H.; VITTHALRAO P. S. Evaluation of different culture media for improvement in bioinsecticides production by indigenous Bacillus thuringiensis and their application against larvae of aedes aegypti. The Scientific World Journal, v. 2014, p. 1-6, 2014.

EL-BENDARY M. A. Bacillus thuringiensis and Bacillus sphaericus biopesticides production J Basic Microbiol, v. 46, p. 158-170, 2006.

GRIZOTTO, R. K. ; BRUNS, R. E. ; DE AGUIRRE, J. M. ; BATISTA, G. Otimização via metodologia de superfície de respostas dos parâmetros tecnológicos para produção de 
fruta estruturada e desidrata a partir da polpa concentrada de mamão. Ciência $e$ tecnologia de alimentos, v. 25(1), p. 158-164, 2005.

LIU, B. L. ; TZENG, Y. M. Optimization of growth medium for the production of spores from Bacillus thuringiensis using response surface methodology. Bioprocess Engineering, v. 18, n. 6, p. 413-418, 1998.

NAGATA T. Carbon and Nitrogen Content of Natural Planktonic Bacteria. Appl Environ Microbiol, v. 52, p. 28-32, 1986.

TARI, C.; GOGUS, N.; TOKATLI, F. Optimization of biomass, pellet size and polygalacturonase production by Aspergillus sojae ATCC 20235 using response surface methodology. Enzyme and Microbial Technology, v. 40, p. 1108-1116, 2007. 